\title{
Mucin in gall bladder bile of gall stone patients: influence of treatment with chenodeoxycholic acid and ursodeoxycholic acid
}

\author{
STAFFAN SAHLIN, ÅKE DANIELSSON, BO ANGELIN, EVA REIHNÉR, \\ ROGER HENRIKSSON, AND KURT EINARSSON
}

From the Department of Surgery, Karolinska Institutet at Danderyd Hospital, Stockholm, Departments of Medicine and Surgery, Karolinska Institutet at Huddinge University Hospital, Stockholm and Departments of Medicine and Histology, University of Umeå, Umeå, Sweden

SUMmaRy The concentration of hexosamine, a marker for mucin, was determined and related to the degree of cholesterol saturation and to the occurrence of cholesterol crystals in gall bladder bile of gall stone patients $(n=40)$ and gall stone free subjects $(n=25)$. Ten of the gall stone patients had been treated with chenodeoxycholic acid (CDCA) and eight with ursodeoxycholic acid (UDCA) three to four weeks before cholecystectomy. The hexosamine content was significantly higher in gall stone patients ( $137(19) \mathrm{ng} / \mathrm{ml}$, mean (SE) than in gall stone free subjects $(83(9) \mathrm{ng} / \mathrm{ml}, \mathrm{p}<0 \cdot 02)$. Treatment with CDCA or UDCA decreased cholesterol saturation, but did not significantly affect the hexosamine concentration. There was no difference in hexosamine concentration between gall stone patients with and without cholesterol crystals. The results do not support the hypothesis that the degree of cholesterol saturation is important for the mucin content of gall bladder bile in man. Neither do the data indicate that the formation and occurrence of cholesterol crystals in gall bladder bile from gall stone patients is caused by an increased concentration of mucin. As the studies were conducted on patients who had already had gall stones for several years, however, an effect of mucin in the very early stage of gall stone formation cannot be completely excluded.

Supersaturated gall bladder bile is necessary for gall stone formation. On the other hand, many gall stone free subjects have saturated bile, and yet do not develop gall stones. ${ }^{12}$ A key factor in the development of gall stones from supersaturated bile is the formation of cholesterol monohydrate crystals - that is, the nucleation process. ${ }^{34}$ Holan et al ${ }^{5}$ found that gall bladder bile from gall stone patients has considerably shorter nucleation time (mean of three days) than supersaturated bile from gall stone free subjects (mean of 15 days). Cholesterol crystal nucleation time thus provides a sharper discrimination between patients with cholesterol gall stones and gall stone free subjects than does cholesterol saturation.

The shorter nucleation time in gall stone patients

Address for correspondence: Dr Staffan Sahlin, Department of Surgery, Danderyd Hospital, S-182 88 Danderyd, Sweden.

Received for publication 13 May 1988. may depend on the presence of nucleating factors, the deficiency of stabilising factors or an imbalance between factors which accelerate and inhibit the nucleation process. ${ }^{34}$ On the basis of studies using animal models and in vitro experiments, several investigators have suggested that gall bladder mucin may play an important role as a nucleating factor. ${ }^{-111}$ Other authors have, however, questioned whether mucin is responsible for the rapid nucleation time in gall stone patients. ${ }^{11} 12$

The aim of the present study was to determine the concentration of hexosamine, a marker for mucin, in gall bladder bile of gall stone free subjects and gall stone patients, and to correlate the findings with the cholesterol saturation and the occurrence of cholesterol crystals. Furthermore, the hexosamine concentration was determined in gall stone patients pretreated with chenodeoxycholic acid (CDCA) or 1506 
make gall bladder bile unsaturated with cholesterol and thus capable to induce gall stone dissolution.

\section{Methods}

\section{PATIENTS}

The study comprised 25 gall stone free subjects and 40 patients undergoing cholecystectomy because of cholesterol gall stones. They were all non-obese (relative body weight less than $125 \%$ ) and normolipidemic and had no clinical or laboratory evidence of ethanol overconsumption, diabetes mellitus, or diseases affecting liver or kidney function. The gall bladder was functioning in all patients as shown by preoperative cholecystography. Indicative of a functioning gall bladder was also dark, concentrated bile in the gall bladder, no impacted stone in the gall bladder neck, and a patent cystic duct. The gall stone free subjects were cholecystectomised because of suspected adenomyoma or polyps of the gall bladder. Ten of the gall stone patients were treated with CDCA and eight with UDCA before operation. Basal data on the patients are given in Table 1. Informed consent was obtained before operation in all cases, and the ethical aspects of the study were approved by the Ethical Committee of Karolinska Institutet, Stockholm.

\section{EXPERIMENTAL PROCEDURE}

Chenodeoxycholic acid and UDCA were administered in a daily dose of $15 \mathrm{mg} / \mathrm{kg}$ body weight for three to four weeks before operation. The medication was well tolerated. Most of the subjects treated with CDCA noted softer stools, and two developed occasional diarrhoea. Body weights remained unchanged.

About two to three days before surgery, the patients were hospitalised and given the regular hospital diet, in which 30,20 , and $50 \%$ of energy is supplied as fat, protein, and carbohydrate, respectively. The daily intake of cholesterol was about 0.5 mmol.

All operations were done between 0800 and 0900 after a 12 hour fast. After opening of the abdomen,

Table 1 Basal data of the patients

\begin{tabular}{|c|c|c|c|c|c|}
\hline \multirow[b]{2}{*}{ Patient group } & \multirow[b]{2}{*}{$n$} & \multirow{2}{*}{$\begin{array}{l}\text { Sex } \\
\text { female/male }\end{array}$} & \multirow{2}{*}{$\begin{array}{l}\text { Age } \\
\text { yrs }\end{array}$} & \multicolumn{2}{|c|}{ Body weight } \\
\hline & & & & $k g$ & Relative* \\
\hline $\begin{array}{l}\text { Gall stone free } \\
\text { Gall stones }\end{array}$ & 25 & $22 / 3$ & $44(3)$ & $66(2)$ & $98(2)$ \\
\hline Untreated & 22 & $15 / 7$ & $48(3)$ & $66(3)$ & $100(3)$ \\
\hline CDCA-treated & 10 & $10 / 0$ & $47(5)$ & $61(2)$ & $99(5)$ \\
\hline UDCA-treated & 8 & $8 / 0$ & $49(5)$ & $64(3)$ & $100(3)$ \\
\hline
\end{tabular}

gall bladder bile was carefully collected by needle aspiration. A regular cholecystectomy was then performed without complications.

MATERIA LS

Chenodeoxycholic acid (Chendal) was obtained from Draco, Sweden, and administered in $125 \mathrm{mg} \mathrm{(0.32}$ mmol) capsules. The preparation was $>99 \%$ pure. Ursodeoxycholic acid was kindly supplied by Tokyo Tanabe Co, Tokyo, Japan, and was shown to be $>98 \%$ pure by gas liquid chromatography. UDCA was administered in $125 \mathrm{mg}(0.32 \mathrm{mmol})$ capsules. $\mathrm{D}-\left[1-{ }^{1+} \mathrm{C}\right]$ Glucosamine hydrochloride $(7.6 \mathrm{mCi} /$ mmol) was purchased from New England Nuclear Corp, Boston, MA. D-Glucosamine hydrochloride was obtained from Sigma Chemical Co, St Louis, MO. 3-alpha-Hydroxysteroid dehydrogenase (Sterognost) and cholesterol oxidase (Nyco-test cholesterol) were purchased from Nyegaard A/S, Oslo, Norway.

\section{ANALYSIS}

All bile samples were examined for cholesterol crystals of monohydrate form by polarizing light microscopy, the microscope slides being prewarmed to $37^{\circ} \mathrm{C}$. An aliquot of the bile sample obtained was immediately extracted with 20 vol of chloroformmethanol, 2:1 (vol/vol). Cholesterol was determined by an enzymatic method ${ }^{13}$ and phospholipids by the method of Rouser et al..$^{14}$ The total bile acid concentration was determined in another aliquot of the bile sample using a 3-alpha-hydroxysteroid dehydrogenase assay. ${ }^{15}$ Cholesterol saturation was calculated according to Carey. ${ }^{16}$ In the UDCA treated patients, the cholesterol saturation of gall bladder bile was calculated with and without the correction factor for UDCA rich bile, as proposed by Carey. ${ }^{16}$

Gall bladder mucin was determined by assay of hexosamine content according to Boas. ${ }^{17}$ To $2 \mathrm{ml}$ of the gall bladder sample was added $0.25 \mu \mathrm{Ci}$ of ${ }^{14} \mathrm{C}$-labelled D-glucosamine as an internal standard. Hydrolysis was performed with $2 \mathrm{ml}$ of $2 \mathrm{M} \mathrm{HCl}$ for two hours. The hydrolysate was diluted with $6 \mathrm{ml}$ distilled water, filtered, passed through a Dowex 50 ion exchange column, washed with distilled water, and eluted with $2 \mathrm{M} \mathrm{HCl}$. Glucosamine hydrochloride was used to establish standard curves. The values obtained were corrected for losses by using the recovery of the added ${ }^{14} \mathrm{C}$-labelled glucosamine. The recovery amounted to $70-75 \%$.

STATISTICAL ANALYSIS

Data are presented as means (SE). The statistical significance of differences was evaluated by Student's $t$ test. Correlations between parameters were tested by estimating the correlation coefficient, $r$. 
Table 2 Lipid concentration, lipid composition and cholesterol saturation of gall bladder bile

\begin{tabular}{|c|c|c|c|c|c|c|}
\hline \multirow[b]{2}{*}{ Patient group (n) } & \multirow{2}{*}{$\begin{array}{l}\text { Lipid conc } \\
\text { g/dl }\end{array}$} & \multicolumn{2}{|l|}{ Cholesterol } & \multirow{2}{*}{$\begin{array}{l}\text { Bile acids } \\
\text { mol\% }\end{array}$} & \multirow{2}{*}{$\begin{array}{l}\text { Phospholipids } \\
\text { mol\% }\end{array}$} & \multirow{2}{*}{$\begin{array}{l}\text { Cholesterol } \\
\text { saturation } \\
\%\end{array}$} \\
\hline & & umol/l bile & $\mathrm{mol} \%$ & & & \\
\hline Gall stone free (25) & $12 \cdot 8(0 \cdot 7) \ddagger$ & $11 \cdot 1(1 \cdot 3)$ & $5 \cdot 5(0 \cdot 3) \ddagger$ & $71 \cdot 5(0 \cdot 9) \ddagger$ & $23 \cdot 0(0 \cdot 7)$ & $74(3) \ddagger$ \\
\hline \multicolumn{7}{|l|}{ Gall stone } \\
\hline Untreated (22) & $7 \cdot 4(1 \cdot 0)$ & $12 \cdot 9(1 \cdot 1)$ & $8 \cdot 6(0 \cdot 5)$ & $66 \cdot 5(0 \cdot 9)$ & $24.9(0.7)$ & $124(8)$ \\
\hline CDCA-treated (10) & $9 \cdot 3(1 \cdot 5)$ & $7 \cdot 6(0 \cdot 9) \ddagger$ & $4.9(0.4) \ddagger$ & $75 \cdot 1(1 \cdot 2) \ddagger$ & $20.9(0.9) \dagger$ & $74(6) \ddagger$ \\
\hline UDCA-treated (8) & $4 \cdot 4(0 \cdot 6)^{*}$ & $3 \cdot 0(0 \cdot 6) \ddagger$ & $4 \cdot 2(0 \cdot 6) \ddagger$ & $69 \cdot 2(4 \cdot 7)$ & $26 \cdot 6(4 \cdot 2)$ & $60(7) \ddagger$ \\
\hline
\end{tabular}

Significantly different from untreated gall stone patients: ${ }^{*} \mathrm{p}<0 \cdot 05 ; \mathrm{p}<0 \cdot 01 ; \neq \mathrm{p}<0.001$.

Means (SE).

\section{Results}

Cholesterol crystals of monohydrate form were found in the gall bladder bile of 16 of the 22 untreated gall stone patients and in only three of the 25 gall stone free subjects. Three of the eight UDCA treated patients and none of those treated with CDCA had crystals.

Data on biliary lipids and cholesterol saturation of gall bladder bile are summarised in Table 2. Gall bladder bile was supersaturated in two of the 25 gall stone free subjects and in all but seven of the 22 untreated gall stone patients. Female and male gall stone patients had similar cholesterol saturation, the mean values being $125 \%$ and $123 \%$, respectively.

A wide range of hexosamine concentrations was observed in the gall stone free subjects and'in the gall stone patients (Figure). No significance was obtained

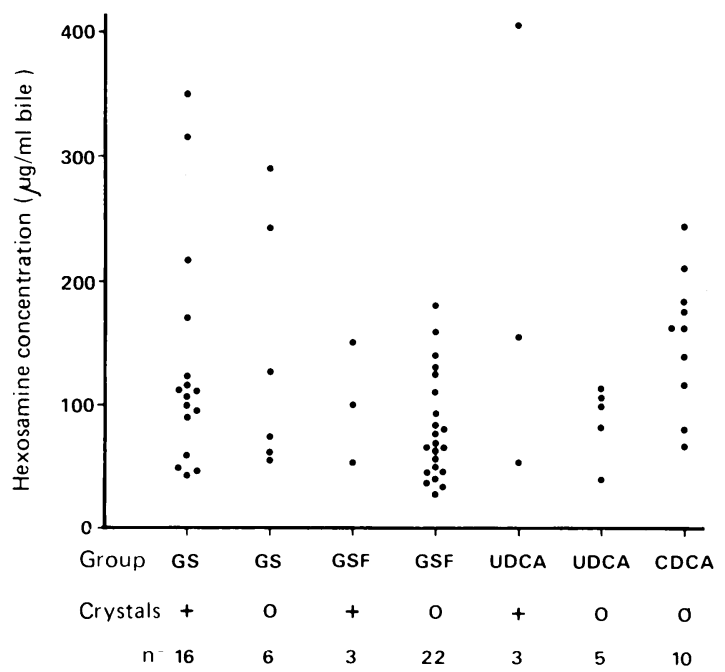

Figure Hexosamine concentration in gall bladder bile of gall stone patients $(G S)$, gall stone free subjects (GSF) and gall stone patients treated with ursodexocycholic acid (UDCA) or chenodeoxycholic acid (CDCA). between female and male gall stone patients, the mean values being $131 \mathrm{ng} / \mathrm{ml}$ and $150 \mathrm{ng} / \mathrm{ml}$, respectively. As shown in Table 3 , the mean concentration of hexosamine in untreated gall stone patients (137 (19) $\mathrm{ng} / \mathrm{ml}$ ) was significantly higher than that of gall stone free subjects $(83(9) \mathrm{ng} / \mathrm{ml})(\mathrm{p}<0.02)$. The hexosamine concentration was similar in the gall stone patients with $(138(21) \mathrm{ng} / \mathrm{ml})$ and without crystals (141 (41) ng/ml) (Figure).

Ursodeoxycholic acid made gall bladder bile unsaturated in all patients and CDCA in all but one of the patients treated, the mean values being $60 \%$ and $74 \%$, respectively (Table 2 ). If Carey's correction factor for UDCA rich bile was taken into account cholesterol saturation was $87(9) \%$. Treatment with CDCA and UDCA did not significantly affect the concentration of hexosamine in gall bladder bile (Figure, Table 3 ).

Statistical significance was obtained for the relation between cholesterol saturation and hexosamine concentration, expressed as $\mu \mathrm{g} / \mathrm{ml}$ of bile, in patients treated with UDCA $(r=+0.81, p<0.02)$ but not in the other groups of patients.

\section{Discussion}

Mucin consists of a large glycoprotein which consists of $70-80 \%$ carbohydrates (monosaccarides) and 20 $30 \%$ protein. A convenient direct method to measure

Table 3 Hexosamine concentration of gall bladder bile

\begin{tabular}{lcc}
\hline & \multicolumn{2}{l}{ Hexosamine concentration } \\
\cline { 2 - 3 } Patient group $(n)$ & $\mu g / m l$ bile & $m g / g$ lipids \\
\hline Gall stone free (25) & $83(9) \dagger$ & $0 \cdot 68(0 \cdot 08)^{*}$ \\
Gall stones & & \\
Untreated (22) & $137(19)$ & $3 \cdot 74(1 \cdot 34)$ \\
CDCA-treated (10) & $151(17)$ & $2 \cdot 05(0 \cdot 45)$ \\
UDCA-treated (8) & $130(42)$ & $4 \cdot 14(1 \cdot 93)$ \\
\hline
\end{tabular}

*Significantly different from untreated gall stone patients, $\mathrm{p}<0 \cdot 05$; $\dagger \mathrm{p}<0 \cdot 02$.

Means (SE). 
mucin in small samples has been lacking. ${ }^{18}$ Therefore, in several human studies and animal experiments, hexosamine, a molecule present only in mucin, has been used as a specific marker for mucin in gall bladder bile. ${ }^{79-21}$ The total hexosamine content has been determined by the method of Boas $^{17}$ using glucosamine to establish standard curves. In vitro the incorporation of radiolabelled glucosamine has proved to be a quantitative method to measure the rate of gall bladder mucin synthesis and secretion. ${ }^{61822}$ Previous studies have shown that the composition as well as the proportion of the carbohydrates in human gall bladder mucin glycoprotein are equal in patients with cholesterol gall stones and gall stone free controls. ${ }^{12324}$ In comparative studies of the mucin content in gall bladder bile of patients with and without gall stones it should thus be accurate to assay hexosamine as a specific, quantitative marker of mucin. In the present work, we have improved the hexosamine assay by adding ${ }^{14} \mathrm{C}$ labelled D-glucosamine as an internal standard to the bile samples, in order to correct for losses during the analytical procedure.

Patients with gall stones displayed significantly higher hexosamine content in gall bladder bile than did gall stone free subjects. Our results thus confirm and extend those of Bouchier et al. ${ }^{19}$ Also Lee et $a l^{24}$ found raised glycoprotein concentration in gall bladder bile of gall stone patients. In contrast, Harvey et $a l^{12}$ reported that the mucin glycoprotein concentration of gall bladder bile in cholesterol gall stone patients and gall stone free subjects were not significantly different. Some of their gall stone patients, however, did have raised levels of mucin glycoprotein. It is thus apparent that gall stone disease is often associated with an increased concentration of mucin in the gall bladder bile. It has long been assumed that the hypersecretion of mucin is a result of irritation of the gall stones. ${ }^{18}$

On the other hand, several animal models have clearly shown that in lithogenic gall bladder bile, hypersecretion of mucin precedes cholesterol crystal and stone formation. ${ }^{67918}$ In the present study no significant correlation among the gall stone free subjects and the untreated gall stone patients between cholesterol saturation and hexosamine concentration was obtained. More important is the fact that treatment of gall stone patients with CDCA or UDCA, which made gall bladder bile unsaturated with cholesterol, did not diminish the hexosamine content. Thus, the present data do not support the hypothesis that the lithogenicity of gall bladder bile is of importance for the mucin content in man.

Does mucin act as a nucleating agent in human gall bladder bile? Recent studies by Levy $e t$ al ${ }^{8}$ and Gallinger et $a l^{\prime \prime}$ have convincingly shown that human gall bladder mucin accelerates nucleation of cholesterol in artificial as well as human bile. This was true also for mucin obtained from subjects without gall stone disease. On the other hand, Harvey et al ${ }^{12}$ could not find any correlation between human gall bladder mucin glycoprotein concentration and cholesterol nucleatin time in vitro. Neither did Whiting and Watts ${ }^{21}$ find any relation between the concentration of biliary hexosamine and the propensity to cholesterol crystal formation in man. In agreement with these data, we did not find any difference in hexosamine concentration between gall stone patients with and without cholesterol crystals in the present study. Smith ${ }^{25}$ recently reported the ability of gall bladder mucin, obtained from patients without gall bladder disease, to bind cholesterol and phospholipids in model bile. Cholesterol binding to mucin was dependent on the degree of cholesterol saturation, being negligible in unsaturated bile but markedly increased in supersaturated bile. It is thus possible that mucin may act as a pronucleating agent in the formation of cholesterol monohydrate crystals in supersaturated bile mainly because of its hydrophobic binding of cholesterol.

In conclusion, the present results do not support the concept that an increased concentration of mucin glycoprotein in gall bladder bile is responsible for crystal formation in cholesterol gall stone patients in vivo. It should be noted, however, that the present studies have been performed on bile samples from patients who had already had stones for several years, and thus do not exclude an effect of mucin in the very early stage of gall stone formation.

The skillful technical assistance of Ms Ann-Christine Andersson, Ms Lisbet Benthin, Ms Marianne Jokkinen and Ms Ingela Svensson is gratefully acknowledged. This investigation was supported by grants from the Swedish Medical Research Council (03X-04793).

\section{References}

1 Grundy SM. Factors affecting biliary lipid composition. In: Cohen S, Soloway RD, eds. Gallstones. New York, Churchill Livingstone, 1985: 54-71.

2 Einarsson K, Angelin B. Hyperlipoproteinemia, hypolipidemic treatment and gallstone disease. In: Grundy SM, ed. Bile acids and atherosclerosis. New York: Raven Press, 1986: 67-97.

3 Grundy SM. Mechanism of cholesterol gallstone formation. Semin Liver Dis 1983; 3: 97-111.

4 Holzbach RT, Kibe A. Pathogenesis of cholesterol gallstones. In: Cohen S, Soloway RD, eds. Gallstones. New York: Churchill Livingstone, 1985; 73-100.

5 Holan KR, Holzbach RT, Hermann RE, Cooperman 
AM, Claffey WJ. Nucleation time; a key factor in the pathogenesis of cholesterol gallstone disease. Gastroenterology 1979; 77: 611-7.

6 Lee SP, LaMont JT, Carey MC. Role of gallbladder mucus hypersecretion in the evolution of cholesterol gallstones. J Clin Invest 1981; 67: 1712-23.

7 Doty JE, Pitt HA, Kuchenbecker SL, Porter-Fink V. DenBesten LW. Role of gallbladder mucus in the pathogenesis of cholesterol gallstones. Am J Surg 1983; 145: $54-61$.

8 Levy PF, Smith BF, LaMont JT. Human gallbladder mucin accelerates nucleation of cholesterol in artificial bile. Gastroenterology 1984; 87: 270-5.

9 Zak RA, Frenkiel PG, Marks JW, Bonorris GG, Allen A, Schoenficld LJ. Cyclic nucleotides and glycoproteins during formation of cholesterol gallstones in prairic dogs. Gastroenterology 1984; 87: 263-9.

10 Smith BF, LaMont JT. Gallbladder mucin and gallstone formation. In: Cohen S, Soloway RD, eds. Gallstones. New York: Churchill Livingstone, 1985: 101-11.

11 Gallinger S, Harvey PRC, Petrunka CN, Strasberg SM. The effect of mucous glycoprotein on nucleation time of human bile. Gastroenterology 1985; 89: 648-59.

12 Harvey PRC, Rupar CA, Gallinger S, Petrunka CN, Strasberg SM. Quantitative and qualitative comparison of gallbladder mucus glycoprotein from patients with and without gall stones. Gut 1986; 27: 374-81.

13 Roda A, Festa D, Sama C, et al. Enzymatic determination of cholesterol in bile. Clin Chim Acta 1975; 64: 33741.

14 Rouser G, Sidney F, Akira Y. Two dimensional thinlayer chromatography separation of polar lipids and determinations of phosphorous analysis of spots. Lipids 1979; 5: 494-6.
15 Fausa O. Skălhegg BA. Quantitative determination of bile acids and their conjugates using thin-layer chromatography and purified 3-alphahydroxysteroid dehydrogenase. Scand J Gastroenterol 1974; 9: 249-54.

16 Carey MC. Critical tables for calculating the cholesterol saturation of native bile. J Lipid Res 1978; 19: 945-55.

17 Boas NF. Method for the determination of hexosamines in tissues. J Biol Chem 1953; 204: 5.53-63.

18 LaMont JT, Smith BF, Moore JRL. Role of gallbladder mucin in pathophysiology of gallstones. Hepatology 1984; 4: 51S-6S.

19 Bouchier IAD, Cooperband SR, El Kodsi BM. Mucuous substances and viscosity of normal and pathological human bile. Gastroenterology 1965; 49: 343-53.

20 Neiderhiser D. Thornell E, Björck S, Svanvik J. The effect of lysophophatidylcholine on gallbladder function in the cat. J Lab Clin Med 1983; 101: 699-707.

21 Whiting MJ, Watts J McK. Supersaturated bile from obese patients without gallstones supports cholesterol crystal growth but not nucleation. Gastroenterology 1984; 86: $243-8$.

22 LaMorte VW, LaMont JT, Hale W, Booker ML, Scott TE, Turner B. Gallbladder prostaglandins and lysophospholipids as mediators of mucin secretion during cholelithiasis. Am J Physiol 1986; 251: G701-9.

23 Bouchier IAD, Clamp JR. Glycoproteins in human bile. Clin Chim Acta 1971; 35: 219-24.

24 Lee SP, Lim TH, Scott AJ. Carbohydrate moieties of glycoproteins in human hepatic and gallbladder bile. gallbladder mucosa and gall stones. Clin Sci 1979; 56: 533-8.

25 Smith BF. Human gallbladder mucin binds biliary lipids and promotes cholesterol crystal nucleation in model bile. J Lipid Res 1987; 28: 1088-97. 